\title{
Study of Oblique Propagating Whistler Mode Waves in Presence of Parallel DC Electric Field in Magnetosphere of Saturn
}

\author{
Rajbir Kaur and R.S. Pandey \\ Department of Physics, Amity Institute of Applied Sciences, Amity University \\ Sector -125, Noida, Uttar Pradesh, India \\ *corresponding author, E-mail: rspandey@amity.edu
}

\begin{abstract}
In this paper whistler mode waves have been investigated in magnetosphere of Saturn. The derivation for perturbed distribution function, dispersion relation and growth rate have been determined by using the method of characteristic and kinetic approach. Analytical expressions for growth rate and real frequency of whistlers propagating oblique to magnetic field direction are attained. Calculations have been performed at 6 radial distances in plasma sheet region of Saturn's magnetosphere as per data provided by Cassini. Work has been extended for bi-Maxwellian as well as Loss-cone distribution function. Parametric analysis show that temperature anisotropy, increase in number density, energy density and angle of propagation increases the growth rate of whistler waves along with significant shift in wave number. In case of Loss-cone distribution, increase in growth rate of whistlers is significantly more than for bi-Maxwellian distribution function. Generation of second harmonics can also be seen in the graphs plotted. It is concluded that parallel DC field stabilizes the wave and temperature anisotropy, angle of propagation, number density and energy density of electrons enhances the growth rate. Thus the results are of importance in analyzing observed VLF emissions over wide spectrum of frequency range in Saturnian magnetosphere. The analytical model developed can also be used to study various types of instabilities in planetary magnetospheres.
\end{abstract}

Keywords: Magnetosphere of Saturn, Whistler mode waves, Parallel DC field

\section{Introduction}

Magnetized plasma supports a variety of plasma waves. The investigations done in planet's orbit have shown two general classes of wave-particle interactions, controlling the important aspects of plasma dynamics in magnetospheres, namely, electromagnetic and electrostatic plasma instabilities. In present research we have dealt with resonant interactions between particles trapped in magnetic field lines of Saturn and electromagnetic waves present in background space plasma. Whistlers are low frequency, circularly polarized electromagnetic waves in the audio-frequency range. Whistler mode emission constitutes electromagnetic waves with frequency below either electron gyro frequency or local electron plasma frequency, whatever is less. Since these low frequency whistler mode waves interact with charged particles over long scale lengths within magnetospheres and transfer energy from one region to another, we chose to study them using Electromagnetic Theory. Therefore, this paper work is based on solving Maxwell's equations to understand electromagnetic nature of whistler mode waves in magnetosphere of Saturn.

The Voyager 1 and 2 spacecraft first established that Saturn have many complicated plasma wave phenomena [1-3]. A series of electromagnetic narrowband emissions were identified in inner regions of Saturn's magnetosphere ranging from $3-30 \mathrm{kHz}[1,4]$. The most strongest and complex plasma wave observations at Saturn from Cassini's approach has been reported in inner magnetosphere at radial distance of $\sim 10 \mathrm{Rs}$ [5] (Rs is the radius of Saturn). Many diffused emissions, recognized as whistler mode emissions, were detected at frequencies below electron cyclotron frequency. Whistlers are audio-frequency waves in magnetized plasmas generated by lightning at frequencies below electron cyclotron frequency and electron plasma frequency. The ionosphere/magnetosphere produces various plasma instabilities propagating along the magnetic field lines from one hemisphere to another in plasma mode of propagation called whistler mode [6]. The radial distance of these electromagnetic whistlers is about 2 6 Rs in case of Saturn [7]. Whistlers have also been observed at Jupiter $[9,8]$, at Uranus $[10,11]$ and at Neptune [12].

Accelerating charged particles to kinetic energies much higher than their initial thermal energy is one of the significant phenomena effecting the dynamics of planetary magnetospheres and ionospheres. It can be understood by studying the exchange of mass and energy through electric field parallel to magnetic field [13-15]. Electric field is one the most effecting parameters controlling Saturn's aurorae [16], for interplanetary magnetic field playing a limited role unlike at Earth's. Studies also show that parallel electric fields in acceleration region govern the heating rate of plasma species, along and perpendicular to magnetic field direction. 
Since the electrons are accelerated more effectively by electromagnetic waves at frequencies of few kilohertz [17], thus increasing the growth rate, we investigate whistler mode waves in presence of parallel DC electric field in magnetosphere of Saturn in present work. Statistical approach has been applied to derive dispersion relation. Parametric analysis has been done by calculating the growth rate of whistler mode waves.

\section{Mathematical Formulation}

A homogeneous anisotropic collision less plasma in the presence of an external magnetic field $\mathrm{B}_{\mathrm{o}}=\mathrm{B}_{\mathrm{o}} \hat{\mathrm{e}}_{\mathrm{z}}$ is assumed.

In interaction zone inhomogeneity is assumed to be small. In order to obtain the particle trajectories, perturbed distribution function and dispersion relation, we use the linearized Maxwell's - Vlasov equations. Separating the equilibrium and non-equilibrium parts, neglecting the higher order terms and following the techniques of Misra and Pandey [18] the linearized Maxwell- Vlasov equations are given as:

$\mathrm{v} \cdot\left(\frac{\delta \mathrm{f}_{0}}{\delta \mathrm{r}}\right)+\left(\frac{\mathrm{e}}{\mathrm{m}_{\mathrm{e}}}\right)\left[\frac{\left(\mathrm{v} \times \mathrm{B}_{0}\right)}{\mathrm{c}}\right) \cdot\left(\frac{\delta \mathrm{f}_{0}}{\delta \mathrm{v}}\right)=0$
$\left(\frac{\delta \mathrm{f}_{1}}{\delta \mathrm{t}}\right)+\mathrm{v} \cdot\left(\frac{\delta \mathrm{f}_{1}}{\delta \mathrm{r}}\right)+\left(\frac{\mathrm{F}}{\mathrm{m}_{\mathrm{e}}}\right) \cdot\left(\frac{\delta \mathrm{f}_{1}}{\delta \mathrm{v}}\right)=\mathrm{S}(\mathrm{r}, \mathrm{v}, \mathrm{t})$

Where the Lorentz force is

$\mathrm{F}=\mathrm{e}\left[\frac{\left(\mathrm{v} \times \mathrm{B}_{0}\right)}{\mathrm{c}}\right]=\mathrm{m}_{\mathrm{e}} \frac{\mathrm{dv}}{\mathrm{dt}}$

Where the dispersion relation is defined as

$\mathrm{S}(\mathrm{r}, \mathrm{v}, \mathrm{t})=,-\left(\frac{\mathrm{e}}{\mathrm{m}_{\mathrm{e}}}\right)\left[\frac{\left(\mathrm{v} \times \mathrm{B}_{1}\right)}{\mathrm{c}}\right] \cdot\left(\frac{\delta \mathrm{f}_{\mathrm{so}}}{\delta \mathrm{v}}\right)$

where s denotes the type of electrons. Subscript 'o' denotes the equilibrium values. The perturbed distribution function $\mathrm{f}_{\mathrm{s} 1}$ is determined by using the method of characteristic, which is

$$
\left.\mathrm{f}_{\mathrm{s} 1}(\mathrm{r}, \mathrm{v}, \mathrm{t})=\int_{0}^{\infty} \mathrm{S}\left\{\mathrm{r}_{0}\left(\mathrm{r}, \mathrm{v}, \mathrm{t}^{\prime},\right), \mathrm{v}_{0}\left(\mathrm{r}, \mathrm{v}, \mathrm{t}^{\prime}\right)\right), \mathrm{t}-\mathrm{t}^{\prime}\right\} d \mathrm{t}^{\prime}
$$

We have transformed the phase space coordinate system for $(r, v, t)$ to $\left(r_{0}, v_{0}, t-t^{\prime}\right)$. The particle trajectories that have been obtained by solving equation (3) for given external field configuration are

$$
\begin{aligned}
& \mathrm{X}_{0}=\mathrm{X}+\left(\frac{\mathrm{v}_{\perp} \sin \theta}{\omega_{\mathrm{c}} \mathrm{m}_{\mathrm{e}}}\right)-\left\lfloor\mathrm{v}_{\perp} \sin \left\{\frac{\theta+\omega_{\mathrm{c}} \mathrm{t}}{\omega_{\mathrm{c}} \mathrm{m}_{\mathrm{e}}}\right\}\right] \\
& \mathrm{Y}_{0}=\mathrm{Y}-\left(\frac{\mathrm{v}_{\perp} \cos \theta}{\omega_{\mathrm{c}} \mathrm{m}_{\mathrm{e}}}\right)-\left[\mathrm{v}_{\perp} \cos \left\{\frac{\theta+\omega_{\mathrm{c}} \mathrm{t}}{\omega_{\mathrm{c}} \mathrm{m}_{\mathrm{e}}}\right\}\right]
\end{aligned}
$$

$$
\mathrm{z}_{0}=\mathrm{z}-\frac{\mathrm{v}_{\|}}{\lambda \mathrm{m}_{\mathrm{e}}}
$$

and the velocities are

$$
\begin{aligned}
& \mathrm{v}_{\mathrm{xo}}=\mathrm{v}_{\perp} \cos \left\{\theta+\frac{\omega_{\mathrm{c}} \mathrm{t}}{\mathrm{m}_{\mathrm{e}}}\right\} \\
& \mathrm{v}_{\mathrm{yo}}=\mathrm{v}_{\perp} \sin \left\{\theta+\frac{\omega_{\mathrm{c}} \mathrm{t}}{\mathrm{m}_{\mathrm{e}}}\right\} \\
& \mathrm{v}_{\mathrm{zo}}=\frac{\mathrm{v}_{\|}}{\mathrm{m}_{\mathrm{e}}} \\
& \mathrm{v}_{\mathrm{x}}=\frac{\mathrm{v}_{\perp} \cos \theta}{\mathrm{m}_{\mathrm{e}}}, \mathrm{v}_{\mathrm{y}}=\frac{\mathrm{v}_{\perp} \sin \theta}{\mathrm{m}_{\mathrm{e}}}, \mathrm{v}_{\mathrm{z}}=\frac{\mathrm{v}_{\|}}{\mathrm{m}_{\mathrm{e}}}, \\
& \Gamma_{\mathrm{x}}=\frac{\mathrm{eE}_{\mathrm{o}}}{\mathrm{m}_{\mathrm{e}}}, \omega_{\mathrm{c}}=\frac{\mathrm{eB}_{0}}{\mathrm{~m}_{\mathrm{e}}}
\end{aligned}
$$

$\mathrm{v}_{\perp}$ and $\mathrm{v}_{\|}$denote velocity perpendicular and parallel to the magnetic field. Using equation (6), (7) and the Bessel identity and performing the time integration, following the technique and method of Misra and Pandey [18], the perturbed distribution function is found after some lengthy algebraic simplifications as :

$f_{1}=-\left(\frac{i e}{m_{e} \omega}\right) \sum \operatorname{expi}(m-n) \theta\left[\frac{J_{m} J_{n} U * E_{1 x}-i J_{m} V * E_{1}+J_{m} J_{n} W *}{\omega-\left(\frac{k_{\|} P_{\|}}{m_{e}}+(n+g) \omega_{c}\right)}\right\rfloor$

Due to the phase factor the solution is possible when $\mathrm{m}=\mathrm{n}$. Here.

$\mathrm{U}^{*}=\left(\frac{\mathrm{c}_{1} \mathrm{v}_{\perp} \mathrm{n}}{\lambda_{1} \mathrm{~m}_{\mathrm{e}}}\right)$

$\mathrm{V}^{*}=\left(\frac{\mathrm{c}_{1} \mathrm{v}_{\perp} \mathrm{J}_{\mathrm{n}} \mathrm{J}_{\mathrm{p}}}{\lambda_{1} \mathrm{~m}_{\mathrm{e}}}\right)$

$\mathrm{W}^{*}=\left(\frac{\mathrm{n} \omega_{\mathrm{c}} \mathrm{Fm}}{\mathrm{k}_{\perp} \mathrm{v}_{\perp}}\right)+\left(\mathrm{m}_{\mathrm{e}} \mathrm{v}_{\perp} \omega \frac{\partial \mathrm{f}_{\mathrm{o}}}{\partial \mathrm{v}_{\|}}\right)$

$\mathrm{C}_{1}=\left\{\frac{\mathrm{m}_{\mathrm{e}}}{\mathrm{v}_{\perp}}\right\}\left(\frac{\partial \mathrm{f}_{0}}{\partial \mathrm{v}_{\perp}}\right)\left(\omega-\frac{\mathrm{k}_{\|} \mathrm{v}_{\|}}{\mathrm{m}_{\mathrm{e}}}\right)+\mathrm{k}_{\|} \mathrm{m}_{\mathrm{e}}\left(\frac{\partial \mathrm{f}_{0}}{\partial \mathrm{v}_{\perp}}\right)$

$\mathrm{F}=\frac{\mathrm{Hk}_{\perp} \mathrm{v}_{\perp}}{\mathrm{m}_{\mathrm{e}}}$ 
$\mathrm{H}=\left\{\frac{\mathrm{m}_{\mathrm{e}}^{2}}{\mathrm{v}_{\perp}}\right\}\left(\frac{\partial \mathrm{f}_{0}}{\partial \mathrm{v}_{\perp}}\right)\left(\frac{\mathrm{v}_{\|}}{\mathrm{m}_{\mathrm{e}}}\right)+\mathrm{m}_{\mathrm{e}}\left(\frac{\partial \mathrm{f}_{0}}{\partial \mathrm{v}_{\|}}\right)$

$\mathrm{J}_{\mathrm{n}}\left(\lambda_{1}\right)=\frac{\mathrm{dJ}_{\mathrm{n}}\left(\lambda_{1}\right)}{\mathrm{d} \lambda_{1}}$ and $\mathrm{J}_{\mathrm{n}}\left(\lambda_{2}\right)=\frac{\mathrm{dJ}_{\mathrm{p}}\left(\lambda_{2}\right)}{\mathrm{d} \lambda_{2}}$

The Bessel function arguments are defined as $\lambda_{1}=\frac{\mathrm{k}_{\perp} \mathrm{v}_{\perp}}{\omega_{\mathrm{c}} \mathrm{m}_{\mathrm{e}}}$

The conductivity tensor $\|\sigma\|$ is found to be

$\|\sigma\|=\frac{-i \sum\left(\mathrm{e}^{2} / \mathrm{m}_{\mathrm{e}}\right)^{2} \omega \int \mathrm{d}^{3} \mathrm{v}\|\mathrm{s}\|}{\left[\omega-\left(\frac{\mathrm{k}_{\|} \mathrm{v}_{\|}}{\mathrm{m}_{\mathrm{e}}}\right)-\left(\mathrm{n} \omega_{\mathrm{c}}\right)\right]}$

where

$\|\mathrm{S}\|=\left|\begin{array}{lll}\mathrm{v}_{\perp} \mathrm{J}_{\mathrm{n}}^{2}\left(\frac{\mathrm{n}}{\lambda_{1}}\right) \mathrm{U} * & \mathrm{iv}_{\perp} \mathrm{J}_{\mathrm{n}} \mathrm{V}^{*} & \mathrm{v}_{\perp} \mathrm{J}_{\mathrm{n}}^{2}\left(\frac{\mathrm{n}}{\lambda_{1}}\right) \mathrm{W} \\ \mathrm{v}_{\perp} \mathrm{J}_{\mathrm{n}} \mathrm{J}_{\mathrm{n}}\left(\frac{\mathrm{n}}{\lambda_{1}}\right) \mathrm{U} * & \mathrm{iv}_{\perp} \mathrm{J}_{\mathrm{n}} \mathrm{V}^{*} & \mathrm{v}_{\perp} \mathrm{J}_{\mathrm{n}}\left(\frac{\mathrm{n}}{\lambda_{1}}\right) \mathrm{W} * \\ \mathrm{v}_{\|} \mathrm{J}_{\mathrm{n}}^{2}\left(\frac{\mathrm{n}}{\lambda_{1}}\right) \mathrm{U} * & \mathrm{iv}_{\|} \mathrm{J}_{\mathrm{n}} \mathrm{V}^{*} & \mathrm{v}_{\|} \mathrm{J}_{\mathrm{n}}^{2}\left(\frac{\mathrm{n}}{\lambda_{1}}\right) \mathrm{W}\end{array}\right|$

By using these in the Maxwell's equations we get the dielectric tensor,

$\varepsilon_{\mathrm{ij}}=1+\sum\left\{\frac{4 \mathrm{e}^{2} \pi}{\left(\mathrm{m}_{\mathrm{e}}\right)^{2} \omega}\right\} \int \frac{\mathrm{d}^{3} \mathrm{v}\|\mathrm{S}\|}{\left(\omega-\frac{\mathrm{k}_{\|} \mathrm{v}_{\|}}{\mathrm{m}_{\mathrm{e}}}\right)-\left\{\mathrm{n} \omega_{\mathrm{c}}\right\}}$

For parallel propagating whistler mode instability, the general dispersion relation reduces to $\varepsilon_{11} \pm \varepsilon_{12}=\mathrm{N}^{2}$ where $\mathrm{N}^{2}=\frac{\mathrm{k}^{2} \mathrm{c}^{2}}{\omega^{2}}$

- The dispersion relation for relativistic case with perpendicular $\mathrm{AC}$ electric field for $\mathrm{g}=0, \mathrm{p}=1, \mathrm{n}=1$ is written as:

$\left.\frac{\mathrm{k}^{2} \mathrm{c}^{2}}{\omega^{2}}=1+\frac{4 \mathrm{e}_{\mathrm{s}}^{2} \pi}{\mathrm{m}_{\mathrm{e}} \omega^{2}} \int \frac{\mathrm{d}^{3} \mathrm{v}}{2}\left[\left(\omega-\frac{\mathrm{k}_{\|} \mathrm{v}_{\|}}{\mathrm{vm}_{\mathrm{e}}}\right) \frac{\partial \mathrm{f}_{0}}{\partial \mathrm{v}_{\perp}} \mathrm{m}_{\mathrm{e}}+\mathrm{v}_{\perp} \mathrm{k}_{\|} \frac{\partial \mathrm{f}_{0}}{\partial \mathrm{v}_{\|}}\right] \frac{\mathrm{v}_{\perp}}{\mathrm{m}_{\mathrm{e}}} \frac{1}{\left(\omega-\frac{\mathrm{k}_{\|} \mathrm{v}_{\|}}{\mathrm{m}_{\mathrm{e}}}-\omega_{\mathrm{c}}\right.}\right)$

The generalized distribution function $[19,20]$ is given as

$\mathrm{f}_{0}=\left\{\frac{\mathrm{n}_{\mathrm{o}} \mathrm{v}_{\perp}^{2 \mathrm{j}}}{\pi^{3 / 2} \mathrm{v}_{\mathrm{o} \perp}^{2(j+1)} \mathrm{v}_{\mathrm{o} \|}^{\prime} \mathrm{j} !}\right\} \exp \left[-\left(\frac{\mathrm{v}_{\perp}}{\mathrm{v}_{\mathrm{o} \perp}}\right)^{2}-\left(\frac{\mathrm{v}_{\|}}{\mathrm{v}_{\mathrm{o} \|}^{\prime}}\right)^{2}\right]$
When the applied electric field is parallel to $B_{0}$, it modifies electron thermal velocity in direction of magnetic field.

Therefore, changing $\mathrm{v}_{\mathrm{o}||}$ to a complex quantity $\mathrm{v}_{\mathrm{o} \|}$ given as:

$\mathrm{v}_{\mathrm{o} \|}^{\prime}=\mathrm{v}_{\mathrm{o} \|}\left(1-\frac{\mathrm{ie} \mathrm{E}_{\mathrm{o}}}{\mathrm{m}_{\mathrm{e}} \mathrm{v}_{\mathrm{o} \|}^{2} \mathrm{k}}\right)^{1 / 2}$

Juhl and Treumann [21] explained that modified thermal velocity effects the parallel temperature $T_{\|}$and it changes to another complex quantity $\mathrm{T}_{\|}^{\prime}$. Similarly, temperature anisotropy $\mathrm{A}_{\mathrm{T}}=\frac{\mathrm{T}_{\perp}}{\mathrm{T}_{\|}}$changes to $\mathrm{A}_{\mathrm{T}}{ }^{\prime}=\frac{\mathrm{T}_{\perp}}{\mathrm{T}_{\|}^{\prime}}$.

Substituting electron plasma frequency $\omega_{\mathrm{p}}^{2}=4 \mathrm{e}_{\mathrm{s}}^{2} \pi \mathrm{n}_{\mathrm{o}} / \mathrm{m}_{\mathrm{e}}$ and integrating equation (9) by parts, the dispersion relation is found. Using equations (10) and (11) and doing some lengthy integrals the general dispersion relation becomes

$$
\frac{\mathrm{k}^{2} \mathrm{c}^{2}}{\omega^{2}}=1+\frac{\omega_{\mathrm{p}}^{2}}{\omega^{2}}\left\lfloor\frac{\mathrm{m}_{\mathrm{e}} \omega}{\mathrm{k}_{\|} \mathrm{v}_{0 \|}} \mathrm{Z}(\xi)+\mathrm{A}_{\mathrm{T}}{ }^{\prime}(1+\xi \mathrm{Z}(\xi))\right\rfloor
$$

Where,

$A_{\mathrm{T}}{ }^{\prime}=\theta^{\prime}-1, \theta^{\prime}=(j+1)\left(\frac{\mathrm{v}_{\mathrm{o} \perp}}{\mathrm{v}_{\mathrm{o} \|}^{\prime}}\right)^{2}$

Hence, $\mathrm{A}_{\mathrm{T}}{ }^{\prime}=\mathrm{A}_{\mathrm{T}}+\frac{\mathrm{iE} \mathrm{E}_{\mathrm{o}} \mathrm{e} \theta}{\mathrm{m}_{\mathrm{e}} \mathrm{v}_{\mathrm{o} \|}^{2} \mathrm{k}_{\|}}$with $\theta=(\mathrm{j}+1)\left(\frac{\mathrm{v}_{\mathrm{o} \perp}}{\mathrm{v}_{\mathrm{o} \|}}\right)^{2}$

And $Z(\xi)$ is the plasma dispersion function, written as

$$
\mathrm{Z}(\xi)=\mathrm{i} \sqrt{\pi} \exp \left(-\xi^{2}\right)-\frac{1}{\xi}\left(1+\frac{1}{2 \xi^{2}}\right) \text { with } \quad \xi=\frac{\mathrm{m}_{\mathrm{e}} \omega-\mathrm{m}_{\mathrm{e}} \omega_{\mathrm{c}}}{\mathrm{k}_{\|} \mathrm{v}_{\mathrm{o} \|}^{\prime}}
$$

For real $\mathrm{k}$ and substituting $k^{2} c^{2} / \omega^{2}>>1$, using an asymptotic expansion of $\mathrm{Z}(\xi)$ in the limit of a large value of $\xi$, for $\omega=\omega_{\mathrm{r}}+\mathrm{i} \gamma$, rewriting the dispersion relation as:

$\mathrm{D}=\operatorname{Re}(\mathrm{D})+\mathrm{i} \operatorname{Im}(\mathrm{D})$

Further, growth rate becomes:

$$
\frac{\gamma}{\omega_{c}}=\left.\frac{-\operatorname{ImD}(\omega, \mathrm{k})}{(\partial / \partial \omega) \operatorname{ReD}(\omega, \mathrm{k})}\right|_{\omega=\omega_{\mathrm{r}}}
$$


The expression for growth rate for real frequency $\omega_{\mathrm{r}}$ in dimensionless form is found to be

$$
\frac{\gamma}{\omega_{\mathrm{c}}}=\frac{\frac{\sqrt{\pi}}{\widetilde{\mathrm{k}} \cos \theta}\left(\mathrm{A}_{\mathrm{T}}-\frac{\mathrm{X}_{3}}{1-\mathrm{X}_{3}}\right)\left(1-\mathrm{X}_{3}\right)^{3} \exp \left\{-\left(\frac{1-\mathrm{X}_{3}}{\widetilde{\mathrm{k}} \cos \theta}\right)\right\}^{2}+\frac{\mathrm{E}_{\mathrm{o}} \widetilde{\mathrm{k}} \cos \theta \mathrm{o}}{2 \omega_{\mathrm{c}} \mathrm{m}_{\mathrm{e}} \mathrm{v}_{\mathrm{o}}}\left(1-\frac{\lambda \mathrm{X}_{3}}{1 \mathrm{X}_{3}}\right)}{1+\frac{\widetilde{\mathrm{k}}^{2} \cos ^{2} \theta}{2\left(1-\mathrm{X}_{3}\right)^{2}}+\frac{2 \widetilde{\mathrm{k}}^{2} \cos ^{2} \theta}{2\left(1-\mathrm{X}_{3}\right)}\left(\mathrm{A}_{\mathrm{T}}+\frac{\mathrm{X}_{3}}{2\left(1-\mathrm{X}_{3}\right)}\right)}
$$

$\mathrm{X}_{3}=\frac{\widetilde{\mathrm{k}}^{2} \cos ^{2} \theta}{2 \beta_{1}}\left[1+\mathrm{A}_{\mathrm{T}} \beta_{1}\right]$

Where $\tilde{\mathrm{k}}=\frac{\mathrm{k}_{\|} \mathrm{v}_{\mathrm{o} \|}}{\mathrm{m}_{\mathrm{e}} \omega_{\mathrm{c}}}, \mathrm{X}_{3}=\frac{\omega_{\mathrm{r}}}{\omega_{\mathrm{c}}}, \beta_{1}=\frac{\mathrm{k}_{\mathrm{B}} \mathrm{T}_{\|} \mu_{0} \mathrm{n}_{0}}{\mathrm{~B}_{0}^{2}}$

\section{Results and Discussion}

Growth rate for whistler mode waves is calculated by incorporating spacecraft data in equation no. 15 derived in previous section of the manuscript. Magnetic field magnitude $\left(\mathrm{B}_{\mathrm{o}}\right)$ at radial distance $6 \mathrm{Rs}$ is reported to be $80 \mathrm{nT}$ with thermal energy of electrons $\left(\mathrm{K}_{\mathrm{B}} \mathrm{T}_{\|}\right)$in the range of hundreds of electron volts considered $400 \mathrm{eV}$. Waves are assumed to be propagating at an angle with respect to magnetic field direction in presence of parallel DC field. The angle of propagation is varied as $20^{\circ}, 25^{\circ}$ and $30^{\circ}$. Effect of other parameters like temperature anisotropy and number density of electrons $\left(\mathrm{n}_{\mathrm{o}}\right)$ as $0.5 \times 10^{6} \mathrm{~m}^{-3}, 1 \times 10^{6} \mathrm{~m}^{-3}$ and $1.5 \times 10^{6} \mathrm{~m}^{-3}$ are also analyzed [15].

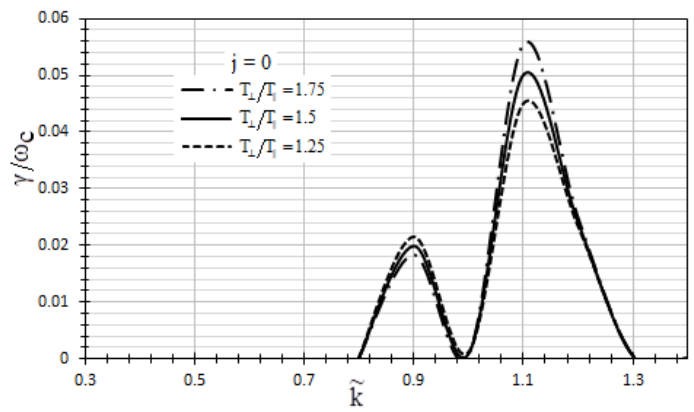

Fig.1: Variation of Growth Rate with respect to $\widetilde{k}$ for various values of $T_{\perp} / T_{\|}$at other plasma parameters being

$$
\mathrm{B}_{\mathrm{o}}=80 \mathrm{nT}, \mathrm{K}_{\mathrm{B}} \mathrm{T}_{\|}=400 \mathrm{eV}, \mathrm{n}_{\mathrm{o}}=1 \times 10^{6} \mathrm{~m}^{-3} \text { and } \theta=30^{\circ} \text {. }
$$

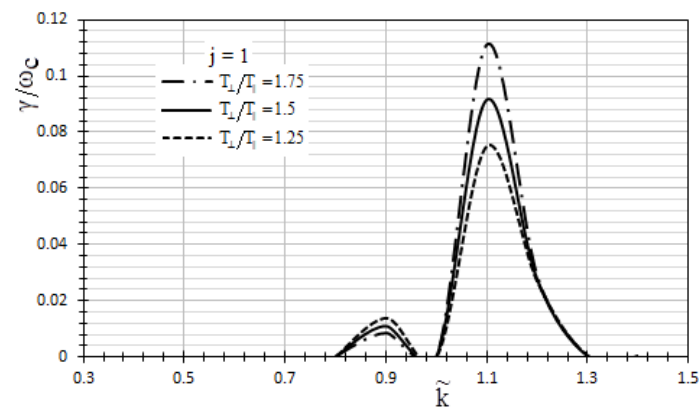

Fig.2: Variation of Growth Rate with respect to $\widetilde{k}$ for various values of $T_{\perp} / T_{\|}$at other plasma parameters being

$$
\mathrm{B}_{0}=80 \mathrm{nT}, \mathrm{K}_{\mathrm{B}} \mathrm{T}_{\|}=400 \mathrm{eV}, \mathrm{n}_{\mathrm{o}}=1 \times 10^{6} \mathrm{~m}^{-3} \text { and } \theta=30^{\circ} \text {. }
$$

Comparison has been done between figure 1 and 2, showing the variation of growth rate $\left(\gamma / \omega_{c}\right)$ with respect to wave number $(\widetilde{\mathrm{k}})$ for various values of ratio of perpendicular temperature to parallel temperature $\left(T_{\perp} / T_{\|}\right)$. As $\mathrm{T}_{\perp} / \mathrm{T}_{\|}-1=\mathrm{A}_{\mathrm{T}}$, these graphs show the effect of temperature anisotropy on growth rate of whistlers. Graphs show generation of second harmonics for higher wave number ranging from 0.8 to 1.3 . In figure 1 and 2 , we can see significant difference in magnitude of growth rate of whistler mode waves for bi-Maxwellian and Loss-cone distribution function. Double peak can be observed in both the graphs at same wave numbers $\widetilde{\mathrm{k}}=0.9$ and $\widetilde{\mathrm{k}}=1$.1. In figure 1 , for biMaxwellian distribution function maximum growth rate calculated for $T_{\perp} / T_{\|}=1.25,1.5$ and 1.75 is $0.0451,0.0501$ and 0.0555 respectively. Whereas in figure 2 , using Loss cone distribution function maximum growth rate is $0.0751,0.0915$ and 0.1112 for $\mathrm{T}_{\perp} / \mathrm{T}_{\|}=1.25,1.5$ and 1.75 respectively. Magnitude of growth rate for second peak is higher for loss cone distribution function but more for first peak in biMaxwellian case. Effect of parallel electric field on electrostatic ion-cyclotron instability shows that steepness of loss-cone and temperature anisotropy enhances the growth rate and reduces transverse acceleration of ions [23].

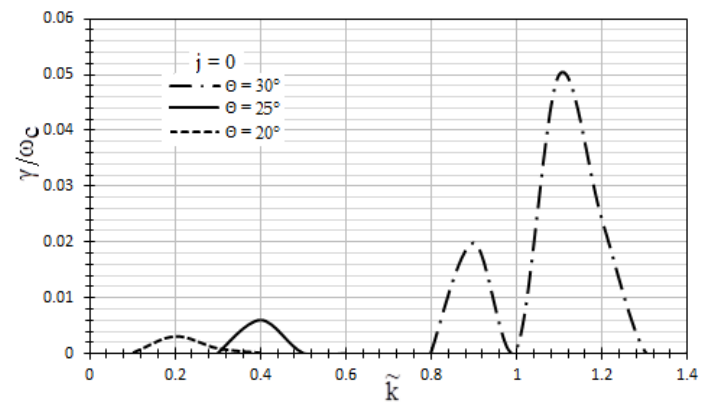


Fig.3: Variation of Growth Rate with respect to $\tilde{\mathrm{k}}$ for various values of $\theta$ at other plasma parameters being $B_{0}=80$ $\mathrm{nT}, \mathrm{K}_{\mathrm{B}} \mathrm{T}_{\|}=400 \mathrm{eV}, \mathrm{n}_{\mathrm{o}}=1 \times 10^{6} \mathrm{~m}^{-3}$ and $\mathrm{T}_{\perp} / \mathrm{T}_{\|}=1.5$.

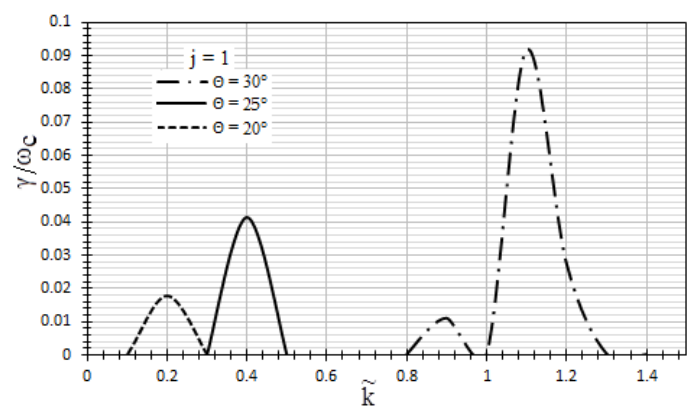

Fig.4: Variation of Growth Rate with respect to $\widetilde{k}$ for various values of $\theta$ at other plasma parameters being $B_{0}=$ $80 \mathrm{nT}, \mathrm{K}_{\mathrm{B}} \mathrm{T}_{\|}=400 \mathrm{eV}, \mathrm{n}_{\mathrm{o}}=1 \times 10^{6} \mathrm{~m}^{-3}$ and $\mathrm{T}_{\perp} / \mathrm{T}_{\|}=1.5$.

Figure 3 and 4 show the variation of dimensionless growth rate versus wave number for different values of angle of propagation of whistler mode waves with respect to magnetic field direction. Using bi-Maxwellian distribution function $\mathrm{j}=0$ in figure 3, maximum growth rate calculated for $\theta=20^{\circ}, 25^{\circ}$ and $30^{\circ}$ is $0.0031,0.0060$ and 0.0501 respectively. Using Loss cone distribution function $\mathrm{j}=1$ in figure 4 , maximum growth rate calculated for $\theta=20^{\circ}, 25^{\circ}$ and $30^{\circ}$ is $0.0178,0.0414$ and 0.0915 respectively. Peak value of growth rate for each angle appears at same wave number in both the graphs, $\widetilde{\mathrm{k}}=0.2,0.4$ and 1.1 for $\theta=20^{\circ}, 25^{\circ}$ and $30^{\circ}$ respectively. Although there is no shift in wave number but difference in magnitude of growth rate in both the graphs can clearly be seen. Such shift in wave number could not be observed in terrestrial and planetary magnetospheres $[22,24,25]$. Also the plot shows that second harmonics are not generated at lower angles of propagation and growth rate increases for increasing value of angle of propagation.

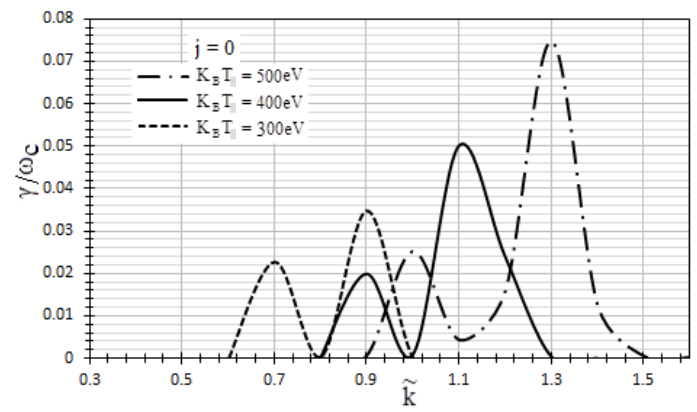

Fig.5: Variation of Growth Rate with respect to $\widetilde{\mathrm{k}}$ for various values of $\mathrm{K}_{\mathrm{B}} \mathrm{T}_{\|}$at other plasma parameters being $\mathrm{B}_{0}=$ $80 \mathrm{nT}, \theta=30^{\circ}, \mathrm{n}_{\mathrm{o}}=1 \times 10^{6} \mathrm{~m}^{-3}$ and $\mathrm{T}_{\perp} / \mathrm{T}_{\|}=1.5$.

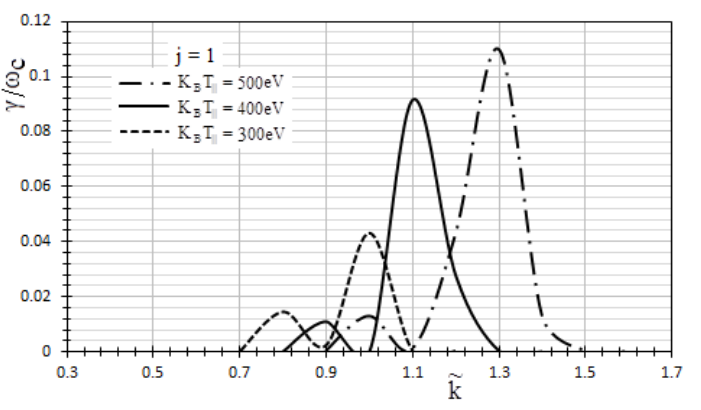

Fig.6: Variation of Growth Rate with respect to $\widetilde{k}$ for various values of $K_{B} T_{\|}$at other plasma parameters being $B_{0}=$ $80 \mathrm{nT}, \theta=30^{\circ}, \mathrm{n}_{\mathrm{o}}=1 \times 10^{6} \mathrm{~m}^{-3}$ and $\mathrm{T}_{\perp} / \mathrm{T}_{\|}=1.5$.

Figure 5 and 6 show the variation of dimensionless growth rate with respect to wave number for different values of energy density $\left(\mathrm{K}_{\mathrm{B}} \mathrm{T}_{\|}\right)$of electrons using bi-Maxwellian and Loss cone distribution function respectively. At radial distance of $6 \mathrm{R}_{\mathrm{S}}$, generation of second harmonics can be noted from both the graphs. In figure 5, with thermal energy $300 \mathrm{eV}$, two peak values of $\gamma / \omega_{c}$ is 0.0227 and 0.0347 at $\widetilde{k}=0.7$ and 0.9 respectively. Similarly, for $\mathrm{K}_{\mathrm{B}} \mathrm{T}_{\|}=400 \mathrm{eV}$, peak values of $\gamma / \omega_{\mathrm{c}}$ is 0.0199 and 0.0501 at $\widetilde{\mathrm{k}}=0.9$ and $1.1 \mathrm{resp}$. And for $\mathrm{K}_{\mathrm{B}} \mathrm{T}_{\|}=500 \mathrm{eV}$, two peak values of $\gamma / \omega_{\mathrm{c}}$ is 0.0251 and 0.0747 at $\tilde{\mathrm{k}}=1.0$ and 1.3 resp. The calculations performed assuming the Loss cone distribution function show that for $\mathrm{K}_{\mathrm{B}} \mathrm{T}_{\|}=300 \mathrm{eV}$, two peak values of $\gamma / \omega_{\mathrm{c}}$ is 0.0143 and 0.0430 at $\widetilde{\mathrm{k}}=0.9$ and 1.0 , for $\mathrm{K}_{\mathrm{B}} \mathrm{T}_{\|}=400 \mathrm{eV}$, two peak values of $\gamma / \omega_{c}$ is 0.0109 and 0.0915 at $\widetilde{k}=0.9$ and 1.1 and for $K_{B} T_{\|}$ $=500 \mathrm{eV}$, two peak values of $\gamma / \omega_{\mathrm{c}}$ is 0.0128 and 0.1097 at $\widetilde{\mathrm{k}}=0.9$ and 1.3 respectively. It can be concluded from both the graphs as electrons possessing higher energies undergo waveparticle interaction, growth rate of whistler mode waves increases. As the graphs are widely spread along the range of wave number $(\widetilde{\mathrm{k}}=0.7$ to 1.5$)$, energy density acts as one of the parameters varying which wide spectrum can be analyzed. Results can be compared with previous work done for parallel propagating whistler mode waves in relativistic plasma of magnetosphere of Uranus [26] to present comparative planetary study. 


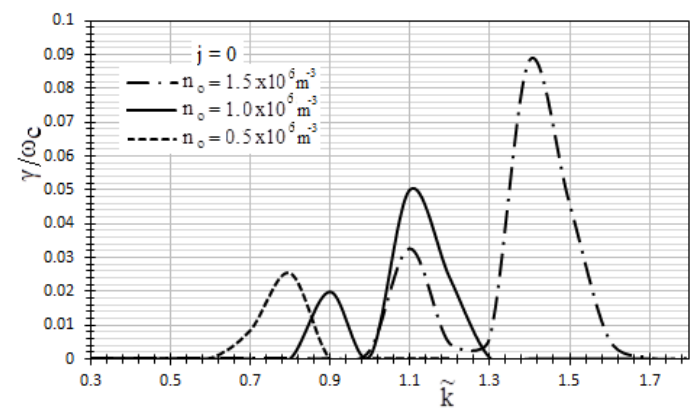

Fig.7: Variation of Growth Rate with respect to $\widetilde{\mathrm{k}}$ for various values of $\mathrm{n}_{0}$ at other plasma parameters being $\mathrm{B}_{0}=80$ $\mathrm{nT}, \theta=30^{\circ}, \mathrm{K}_{\mathrm{B}} \mathrm{T}_{\|}=400 \mathrm{eV}$ and $\mathrm{T}_{\perp} / \mathrm{T}_{\|}=1.5$.

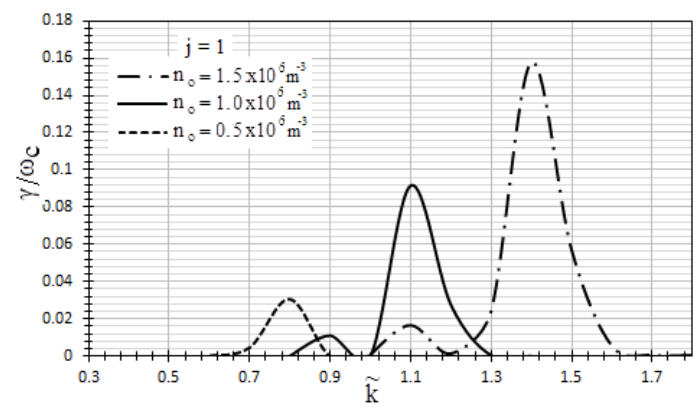

Fig.8: Variation of Growth Rate with respect to $\widetilde{\mathrm{k}}$ for various values of No at other plasma parameters being $\mathrm{B}_{0}=$ $80 \mathrm{nT}, \theta=30^{\circ}, \mathrm{K}_{\mathrm{B}} \mathrm{T}_{\|}=400 \mathrm{eV}$ and $\mathrm{T}_{\perp} / \mathrm{T}_{\|}=1.5$.

Figure 7 and 8 show the variation of dimensionless growth rate with respect to wave number for different values of number density $\left(\mathrm{n}_{\mathrm{o}}\right)$ of electrons. Using bi-Maxwellian distribution function, calculated growth rate for lower number density $\mathrm{n}_{0}=0.5 \times 10^{6} \mathrm{~m}^{-3}$ is 0.0253 at $\widetilde{\mathrm{k}}=0.8$. For higher number density double peak can be seen in graph. For $\mathrm{n}_{0}=1 \times 10^{6} \mathrm{~m}^{-3}$, peak values of growth rate are 0.0199 and 0.0501 at $\widetilde{\mathrm{k}}=0.9$ and 1.1 resp. As the number density increases to $\mathrm{n}_{0}=1.5 \times 10^{6} \mathrm{~m}^{-}$ ${ }^{3}$, growth rate increases to 0.0325 at $\widetilde{\mathrm{k}}=1.1$ and to 0.0882 at $\widetilde{\mathrm{k}}=1.4$. Similarly, while applying Loss cone distribution $\mathrm{j}=1$ in figure 8 , for $\mathrm{n}_{0}=0.5 \times 10^{6} \mathrm{~m}^{-3}$ growth rate is 0.0303 at $\widetilde{\mathrm{k}}=0.8$. For higher number density double peak can be seen in graph. For $\mathrm{n}_{\mathrm{o}}=1 \times 10^{6} \mathrm{~m}^{-3}$, peak values of growth rate are 0.0109 and 0.0915 at $\widetilde{\mathrm{k}}=0.9$ and $1.1 \mathrm{resp}$. And for $\mathrm{n}_{\mathrm{o}}=1.5 \times 10^{6} \mathrm{~m}^{-3}, \gamma / \omega_{\mathrm{c}}$ $=0.0162$ first peak value at $\widetilde{\mathrm{k}}=1.1$ and $\gamma / \omega_{\mathrm{c}}=0.1575$ at $\tilde{\mathrm{k}}$ $=1.4$. Therefore second harmonics are generated at higher number density of electrons in magnetosphere of Saturn.

\section{Conclusion}

Analyzing the results drawn from expression of growth rate and all the graphs plotted in presence of parallel DC field, it can be concluded that magnitude of growth rate of whistler mode waves in case of Loss-cone distribution function is much more than in case of bi-Maxwellian distribution function. Variation in temperature anisotropy shows the generation of second harmonics although for increasing value of $T_{\perp} / T_{\|}$, growth rate increases at same wave numbers. On the contrast, decrease in angle of propagation shows the drastic shift of growth towards lower wave number without generation of second harmonics for lesser value of $\theta$. Studying the increase of energy density of electrons, gradual shift in increasing peaks of growth rate from lower to higher wave numbers can be observed. Also it can be concluded that second harmonics are generated only for higher number density of electrons around radial distance of $6 \mathrm{Rs}$ in magnetosphere of Saturn. Thus the results are of importance in analyzing observed VLF emissions over wide spectrum of frequency range in Saturnian magnetosphere. Thus it is found that parallel DC field stabilizes the wave and temperature anisotropy, angle of propagation, number density and energy density of electrons enhances the growth rate. The analytical model developed can also be used to study various types of instabilities in planetary magnetospheres.

\section{Acknowledgements}

The authors are grateful to the Chairman, Indian Space Research Organisation (ISRO), Director and members of PLANEX program, ISRO, for financial support. We are thankful to Dr. Ashok K. Chauhan (Founder President, Amity University), Dr. Atul Chauhan (President, Amity University) and Dr. Balvinder Shukla (Vice Chancellor, Amity University) for their immense encouragement.

\section{References}

1. Gurnett D. A., Kurth W. S. and Scarf F. L. 1981. Plasma Waves near Saturn: Initial results from Voyager 1. Science 212 (4491): 235

2. Scarf F. L., Gurnett D. A., Kurth W. S. and Poynter R. L. 1982. Voyager2 Plasma Wave Observations at Saturn. Science 215: 587

3. Krimigis S.M., Carbary J.F., Keath E.P., Armstrong T.P., Lanzerotti L.J., Gloeckler G. 1983. General characteristics of hot plasma and energetic particles in the Saturnian magnetosphere: Results from the Voyager spacecraft. J. Geophys. Res. 88: 8871

4. Gurnett D. A., et al. 2004. The Cassini radio and plasma wave investigation. Space Sci. Rev. 114: 395

5. Gurnett, D. A., et al. 2005. Radio and plasma wave observations at Saturn from Cassini's approach and first orbit. Science 307: 1255

6. Storey L.R.O. 1953. An investigation of whistling atmospherics, Philos. Trans. R. Soc. London, Ser. A 246: 113

7. Akalin, F., Gurnett D. A., Averkamp T. F., Persoon A. M., Santolik O., Kurth W. S., and Hospodarsky G. B. 
2006. First whistler observed in the magnetosphere of Saturn. Geophys. Res. Lett. 33: L20107.

8. Scarf F.L., Gurnett D.A and Kurth W.S. 1979. Jupiter plasma wave observations: An initial Voyager 1 overview, Science 204: 991

9. Kurth W.S., Strayer B.D., Gurnett D.A. and Scarf F.L. 1985. A summary of whistlers observed by Voyager 1 at Jupiter, Icarus 61: 497

10. Gurnett, D.A., Kurth, W.S., Scarf, F.L., Poynter, R.L. 1986. First plasma wave observations at Uranus. Science 233: 106

11. Pandey R.S. and Kaur R. 2014. Study of Whistler Mode Wave by Injection of Relativistic Hot Electron Beam in the Magnetosphere of Uranus. Progress in Electromagnetic Research M, Vol. 35: 77

12. Gurnett D.A., Kurth W.S., Cairns I.H. and Granroth L.J. 1990. Whistlers in Neptune's magnetosphere: Evidence of atmospheric lightening, J. Geophys. Res. 95: 20967

13. Marklund et al. 2001. Temporal evolution of the electric field accelerating electrons away from the auroral ionosphere. Nature 414: 724-727

14. Hull A.J., Scudder J.D., Fitzenreiter R.J., Ogilvie K.W., Newbury J.A. and Russell C.T. 2000. Electron temperature and de Hoffmann-Teller potential change across the Earth's bow shock: New results from ISEE 1. J. Geophys. Res., 105(A9): 20957

15. Ergun et al. 2001. Direct observation of localized parallel electric fields in a space plasma. Phys. Rev. Lett. 87: 45003

16. Crary F.J. 2005. Solar wind dynamic pressure and electric field as the main factors controlling Saturn's aurorae. Nature 433: 720

17. Horne et al. 2005. Wave acceleration of electrons in the Van Allen radiation belts. Nature 437: 227

18. Misra K.D. and Pandey R.S. 1995. Generation of whistler emissions by injection of hot electrons in the presence of perpendicular AC electric field. J. Geophys. Res. 100 A(10): 19405

19. Dory R.A., Guest G. E. and Harris E. G. 1965. Unstable Electrostatic Plasma Waves Propagating Perpendicular to a Magnetic Field. Phys. Rev. Lett. 14: 131

20. Sazhin S. S. 1988. Oblique whistler Mode Growth and Damping in a Hot Anisotropic Plasma. Planet Space Science, 36: 663

21. Juhl B. and Treumann R.A. 1985. VLF emission stimulated by parallel electric fields. Journal of Plasma Physics 34(1): 47

22. Pandey R.S. and Kaur R. 2015. Oblique Electromagnetic Electron Cyclotron Waves for Kappa Distribution with A.C Field in Planetary Magnetospheres. Advances in Space Research 56: 714

23. Misra R. and Tiwari M.S. 2006. Effect of parallel electric field on electrostatic ion-cyclotron instability in anisotropic plasma in the presence of ion beam and general distribution function-Particle aspect analysis, Planetary and Space Science 54(2): 188.

24. Pandey R.S. and Kaur R. 2015b. Theoretical study of Electromagnetic Electron Cyclotron Waves in the Presence of AC Field in Uranian Magnetosphere. New Astronomy 40: 41

25. Pandey R.S., Rajbir Kaur, S. Kumar and B.S. Tomar. 2014. Study of Electromagnetic Electron-Cyclotron Waves with Kappa Distribution Function in the Magnetosphere', Journal of Advanced Physics. 3(4) 334

26. Pandey R.S. and Kaur R. 2016. Analytical Study of Whistler Mode waves in Presence of Parallel DC Electric Field for Relativistic Plasma in the Magnetosphere of Uranus. Advances in Space Research, Vol. 58: 1417 